\title{
Diversidade de dípteros de interesse forense com ênfase na taxonomia de Calliphoridae (Diptera), em área urbana e rural de Feira de Santana, Bahia, Brasil
}

\author{
Jéssica Silva Santos ${ }^{1}$; Sergio Ricardo Andena ${ }^{2}$ \\ 1. Bolsista PIBIC/CNPq, Graduando em Ciencias biológicas, Universidade Estadual de Feira de Santana, e-mail: \\ jesssicasantos_silva@hotmail.com \\ 2. Orientador, Departamento de Biologia , Universidade Estadual de Feira de Santana, e-mail: \\ sergioricardoandena@gmail.com
}

PALAVRAS-CHAVE: uma; duas; três.

\section{INTRODUÇÃ̃O}

Os dípteros necrófagos utilizam matéria orgânica em decomposição como fonte protéica em ao menos uma fase de sua vida. Deste modo o conhecimento taxonômico dessa fauna se torna importante para estudos forense, sanitário e médico. Os dípteros das famílias Calliphoridae, Muscidae e Fanniidae possuem espécies necrófagas associadas ao ambiente humano. Existe apenas um estudo em Feira de Santana. Com o objetivo de suprir a falta de informação na região e município, realizou-se este trabalho para propor uma lista de dípteros necrófagos com ênfase em Calliphoridae encontradas na área urbana e rural de Feira de Santana, BA.

\section{MATERIAL E MÉTODOS OU METODOLOGIA (ou equivalente)}

O projeto foi realizado numa área urbana ( Bairro Ponto Central ) e rural ( Distrito de Maria Quitéria )da cidade de Feira de Santana, numa antiga fazenda As coletas foram realizadas bimensalmente com 3 armadilhas iscadas com iscas diferentes ( carne de boi, vísceras de frango e carne de boi), que seguiram metodologia de Hwang \& Turner (2005). As análises estatísticas foram realizadas com o programa Bioestatic 5.3.

\section{RESULTADOS E/OU DISCUSSÃO (ou Análise e discussão dos resultados)}

Foram coletados 4033 exemplares de 11 famílias de dípteros caliptrados, sendo que 2121 das espécimes foram coletados no bairro ponto Central em Feira de Santana e 1920 no distrito de Maria Quitéria. As famílias coletadas neste estudo, na ordem de maior para menor, foram: Calliphoridae (1196), Muscidae 984, Phoridae (807), Fanniidae( 720) Sarcophagidae ( 296), Otitidae (27), Sepsidae (4), Drosopholidae (4) Dolichopodidae (3) Stratiomyidae (2) e Sphaeroceridae (2).

As áreas de estudo segundo o teste $T$ estudant feito pelo programa biostast 5.3 apresentam diferenças significativas em suas mostras em relação às 11 famílias encontradas, mas, segundo o teste, a única família que não teve uma diferença significativa foi Calliphoridae, mostrando um comportamento diferente do estudo Mello et al. (2004) que mostra que Calliphoridae possui uma abundância maior em áreas urbanas.

$\mathrm{Na}$ figura 1, as 5 famílias mais abundantes apresentam uma grande dissimilaridade nas quantidades de espécimes em relação as coletas no período de seca ( novembro e janeiro) Fanniidae, Muscidae e Phoridae apresentam uma queda na quantidade de espécimes coletados durante o período das coletas de novembro e janeiro, seguindo de forma inversa a curva de temperatura, tendo um aumento de espécimes nos meses de temperatura mais baixas e uma diminuição em temperaturas mais elevadas. $\mathrm{O}$ inverso acontece com a família Calliphoridae, que o seu aumento de espécimes coletados ocorre nos meses de maior temperatura. Sarcophagidae não apresenta uma alteração significativa ao longo da coleta 
Segundo Disney (2012), Marchiori \& Prado (1999) e Vasconcelos et al. (2010) Phoridae, Muscidae e Fanniidae são mais ativo entre $22^{\circ} \mathrm{C}-25^{\circ} \mathrm{C}$ e menos em temperaturas acima máximo registrado. Sendo que pra Muscidae e Fanniidae $25^{\circ} \mathrm{C}$ é chamada de ponto ótimo ou ponto de desenvolvimento. As outras 6 famílias (Otitidae, Sepsidae, Drosopholidae, Dolichopodidae, Stratiomyidae e Sphaeroceridae) só apareceram nas coletas de setembro, março e maio, que foi a época de arvores frutíferas presente nos locais darem frutos, isso é explicado por já que 6 espécies são polinizadoras e/ou também utilizam de composto orgânico vegetal para oviposição.

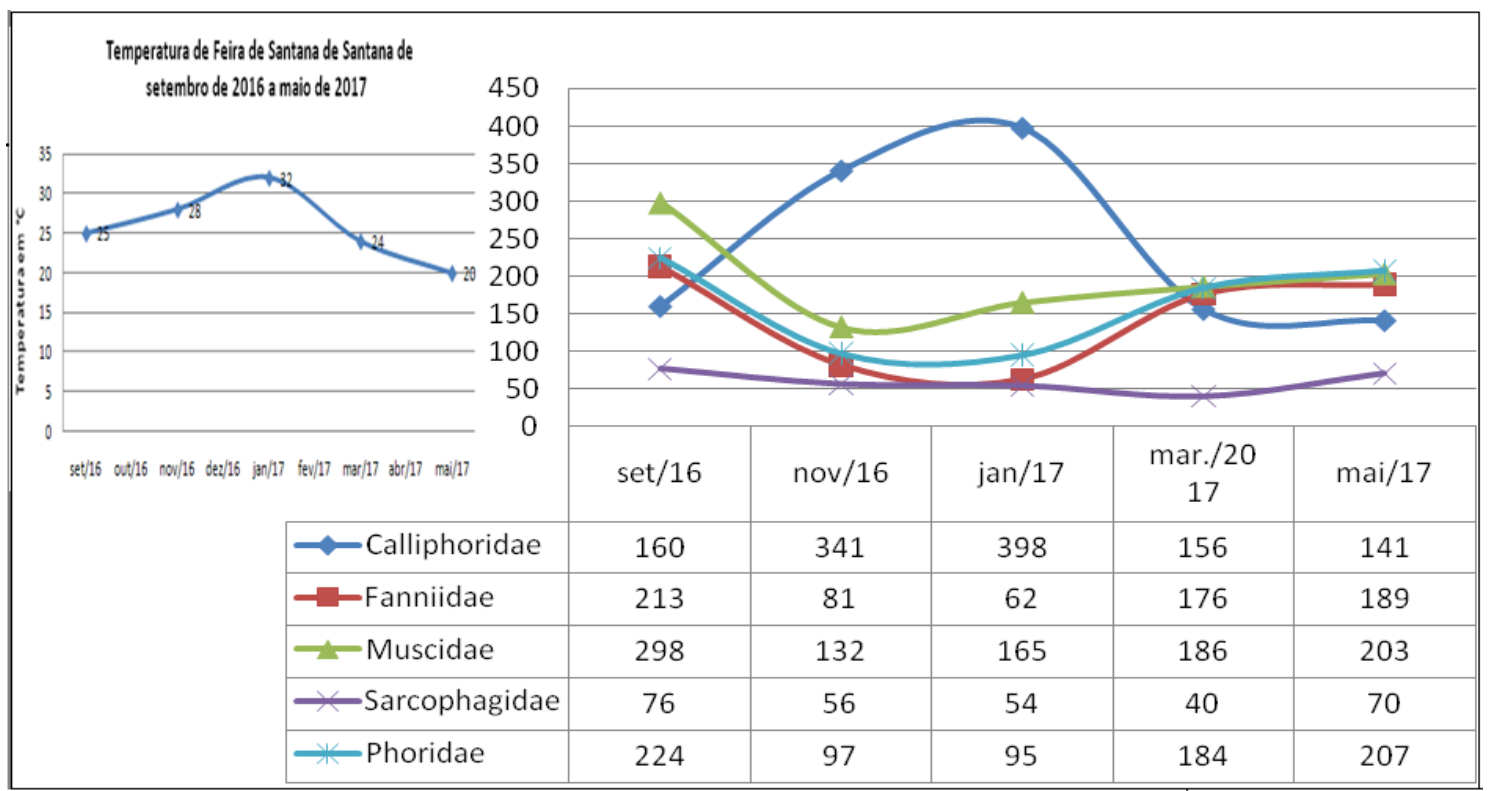

Figura 1: Número de espécimes das famílias mais abundantes em cada mês de coleta.

A analise da curva do coletor de todas as famílias nas duas áreas possuem resultados diferentes, não se estabilizando no centro e estabilizando no Distrito de Maria Quitéria, demonstrando que é necessário mais coletas no centro da cidade de Feira de Santana . A curva do coletor, em relação às espécies Calliphoridae, demonstra que há necessidade de mais coletas pra essa família

Em Calliphoridae os espécimes encontradas pertencem a 15 espécies de 3 subfamílias(Tab. 1). A subfamília com maior riqueza foi Chrysomyinae com sete espécies. Esta família também foi a mais abundante, com $66,8 \%$ das espécimes coletadas de Calliphoridae, contra 31,7\% de Calliphorinae e 1,5\% de Mesembrenellinae. A maior abundancia da subfamília Chrysomyinae é relativo ao número de espécimes coletados (545) de Chrysomya, se tornando o gênero mais abundante de calliphoridae, seguido do gênero Lucilia (190) e de Cochliomyia(189).

As espécies Chrysomya albiceps, Chrysomya megacephala (Fabricius, 1794) e Chrysomya putoria (Wiedemann, 1830), segundo Otsuka (2003) possuem correlação positiva a temperaturas elevadas e uma correlação negativa com diferentes famílias de dípteros. Esses dados podem ajudar a explicar o grande aumento dessa espécie na época de seca e a diminuição de outras famílias nesse mesmo período.

Tabela 1. :Tabela de espécies deCalliphorideos durante o mês de junho

\begin{tabular}{|l|l|l|l|l|l|l|l|}
\hline Famílias/ espécies & set/16 & nov/16 & jan/17 & mar/17 & mai/17 & Total \\
\hline Subfamília Chrysomyinae & \multicolumn{7}{|l|}{} \\
\hline Chrysomya albiceps (Wiedemann, 1819) & 36 & 44 & 87 & 99 & 45 & 311 \\
\cline { 2 - 7 }
\end{tabular}




\begin{tabular}{|c|c|c|c|c|c|c|}
\hline $\begin{array}{l}\text { Chrysomya megacephala (Fabricius, } \\
\text { 1794) }\end{array}$ & 0 & 27 & 48 & 41 & 12 & 128 \\
\hline Chrysomya putoria (Wiedemann, 1818) & 45 & 0 & 22 & 19 & 20 & 106 \\
\hline $\begin{array}{l}\text { Cochliomyia hominivorax (Coquerel, } \\
\text { 1858) }\end{array}$ & 0 & 0 & 0 & 6 & 4 & 10 \\
\hline $\begin{array}{l}\text { Cochliomyia macellaria (Fabricius, } \\
\text { 1775) }\end{array}$ & 0 & 0 & 45 & 82 & 6 & 133 \\
\hline $\begin{array}{l}\text { Chloroprocta idioidea } \\
\text { Desvoidy, 1830) }\end{array}$ & 0 & 16 & 5 & 52 & 17 & 90 \\
\hline Paralucilia xanthogeneiates Dear, 1985 & 4 & 5 & 6 & 6 & 0 & 21 \\
\hline \multicolumn{7}{|l|}{ Calliphorinae } \\
\hline Lucilia cuprina (Wiedemann, 1830) & 6 & 0 & 12 & 8 & 0 & 26 \\
\hline Lucilia eximia (Wiedemann, 1819) & 33 & 4 & 38 & 15 & 16 & 106 \\
\hline Lucilia purpurascens (Walker, 1837) & 0 & 0 & 4 & 0 & 0 & 4 \\
\hline Lucilia sericata (Meigen, 1826) & 0 & 14 & 28 & 9 & 2 & 53 \\
\hline Calliphora lopesi Mello, 1962 & 28 & 20 & 27 & 25 & 3 & 103 \\
\hline $\begin{array}{l}\text { Calliphora vicina Robineau Desvoidy, } \\
1830\end{array}$ & 5 & 26 & 14 & 36 & 6 & 87 \\
\hline \multicolumn{7}{|l|}{ Messembrenellinae } \\
\hline Mesembrinella semihyakina Mello 1967 & 3 & 0 & 5 & 0 & 10 & 18 \\
\hline
\end{tabular}

Também foi realizado neste estudo uma analise de atratividade das iscas. Para a analise dos dados foi utilizado o diagrama de chez (Fig. 2). Três famílias foram atraídas tanto nas iscas de porco quanto pra iscas de frango, duas famílias apenas para de porco e quatro famílias foram atraídas pelas quatro iscas. Sphaeroceridae é a única família que foi atraída exclusivamente para o frango, porém ela é considerada como espécie acidental, já que a sua incidência nas coletas chega a ser menos $10 \%$, sendo, desta forma, necessário excluir os dados dela na análise. Em analise de abundância as iscas não tiveram diferença significativas, mas em termos de riqueza, utilizando o teste $T$, a diferença de cada armadilha difere em $40 \%$.

Quando analisado apenas as duas superfamílias Muscoidea e Oestroidea, que são as superfamílias mais abundantes, percebe que a carne de porco é mais atrativa para a superfamília Muscoidea e a de boi é a menos atrativa e a relação inversa ocorre com a superfamília Oestroidea . A preferência da super superfamília Oestroidea por carne bovina já foi visto em Moretti et al., (2008).Já preferência da super família Muscoidea por carne de porco é um relato novo, mostrando a necessidade de um estudo mais aprofundado para iscas atrativas para dípteros de interesse forense. 


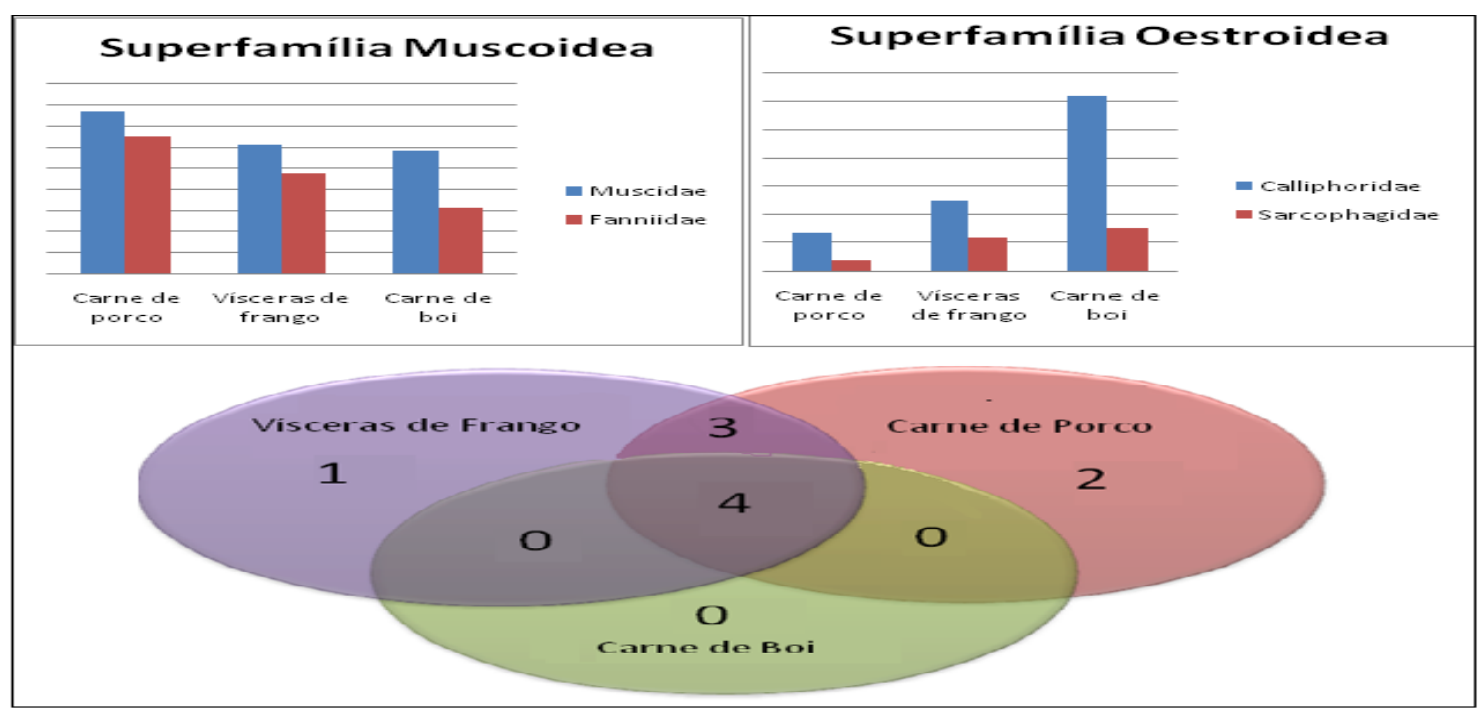

Figura 2. diagrama de chenz e tabelas mostrando a atratividade das 3 iscas : carne de boi, carne de porco e vísceras de frango.

\section{CONSIDERAÇÕES FINAIS (ou Conclusão)}

- Foram 11 famílias coletadas neste estudo, na ordem de maior para menor, foram: Calliphoridae (1196) , Muscidae 984, Phoridae (807), Fanniidae( 720) Sarcophagidae ( 296) , Otitidae (27), Sepsidae (4), Drosopholidae (4) Dolichopodidae (3) Stratiomyidae (2) e Sphaeroceridae (2)

- Neste trabalho, as famílias Muscidae, Phoridae e Fanniidae mostraram que tem uma relação negativa com o período de seca, decaindo em riqueza e diversidade neste período (entre novembro e janeiro), e subindo quando se aproxima do período chuvoso.

- No quesito diversidade e riqueza, a família Calliphoridae, foi a que tem a melhor adaptação a períodos de seca., com o genero Chrysomya é a mais abundante com 545 espécimes

\section{REFERÊNCIAS}

MARCHIORI C.H. \& Prado A.P. 1999. Tabelas de vida de Fannia pusio (Wied.) (Diptera: Fanniidae). An. Soc. Entomol. Bras. 28 (3): 557-563

Mello, R. P., Gredilha, R. , \& Guimarães-Neto, E. G. (2004). Dados preliminares sobre sinantropia de califorídeos (Díptera: Calliphoridae) no municipio de ParacambíRJ. Revista Universidade Rural. Série Ciências da Vida, 24, 97-101.

MORETTI, C. D. T., RIBEIRO, O. B., THYSSEN, J. P., SOLIS, R. D. Insects on decomposing carcasses of small rodents in a secondary Forest in Southeastern Brazil. European Journal of Entomology, vol. CV, p. 691-696, 2008.

OTSUKA, H. Sinantropia e sazonalidade de moscas varejeiras (Diptera: Calliphoridae) no Sudeste do Brasil: Visões ecológica, médica, veterinária e forense. Botucatu: Universidade Estadual Paulista "Júlio de Mesquita Filho", 2003.

Disney, H. Scuttle flies: the Phoridae. Springer Science \& Business Media, 2012.

Hwang C, Turner BD, 2005. Spatial and temporal variability of necrophagous Diptera from urban to rural áreas, Med. Vet. Ent. 19, 379-357 